\title{
A Comparative Study on Morphological and Audiological Outcome in Type I Tympanoplasty for Chronic Otitis Media Mucosal Disease Using Temporalis Fascia versus Cartilage Graft
}

Authors

\section{Amrutha P Raman ${ }^{1}$, Satheesh Somaraj ${ }^{*}$}

${ }^{1}$ Junior Resident, Department of Otorhinolaryngology, Govt. Medical College, Thiruvananthapuram, Kerala, India

${ }^{2}$ Professor and Head, Department of Otorhinolaryngology, Govt. Medical College, Thiruvananthapuram, Kerala, India

*Corresponding Author

Dr Satheesh Somaraj

Professor and Head, Dept of Otorhinolaryngology, Govt Medical College, Thiruvanathapuram,

Kerala, Pin 695011, India

\begin{abstract}
Objective: To compare the morphological and audiological outcome of Type I tympanoplasty in Chronic otitis media mucosal disease using temporalis fascia and cartilage graft.

Materials and Methods: A prospective comparative study among 110 patients with complaints of ear discharge and hearing loss due to Chronic otitis media mucosal disease who underwent Type I tympanoplasty. There were 52 patients where cartilage graft was used and 58 patients where temporalis fascia graft was used. The pre-operative clinical and audiological findings of the study subjects were noted using a proforma. In the post-operative period, they were followed up after 3 months and 6 months. At $3^{\text {rd }}$ month, patients were assessed for perforation closure and audiological evaluation by Tuning Fork Test and Pure Tone Audiometry. At $6^{\text {th }}$ month patients were subjected to clinical examination for integrity of tympanic membrane, PTA and Tympanometry.

Results: Otorrhea was the commonest presenting complaint and majority had a large central perforation. The preoperative hearing loss was between $25 \mathrm{~dB}$ to $45 \mathrm{~dB}$. Majority of the cases had post aural approach for surgery. Tympanosclerosis was seen in 24 patients. Temporalis fascia graft was used in 58 patients, and cartilage graft in 52 patients. Among the temporalis fascia group graft failure was seen in 19 cases while in cartilage graft group there was only 3 cases. The AB gap closure of more than or equal to $10 \mathrm{~dB}$ in temporalis fascia was $82.8 \%$ while that in cartilage graft was $94.2 \%$. The tympanometry curve of A or $C$ was considered as a successful outcome. In 53\% of patients with cartilage graft $A$ or $C$ was obtained, while in temporalis fascia graft group it was $47 \%$. In the short term follow up of 6 months it was found that cartilage graft had reduced chance of re-perforation and better hearing outcome

Keywords: Cartilage graft, Temporalis fascia, Type 1 Tympanoplasty.
\end{abstract}

\section{Introduction}

Chronic otitis media causes permanent pathologic damage to the tympanic membrane and other middle ear structures. The global burden of the disease involves 65-330 million individuals with draining ears and more than half suffering 
significant hearing impairment. ${ }^{1}$ Perforation can result in relapsing infection and deafness which hampers productivity in many individuals.

Tympanoplasty aims to reproduce the natural characteristics of the tympanic membrane in terms of the conduction of the sound and vibration, resistance to negative middle ear pressure and maintenance of structures and middle ear spaces by avoiding long term resorption. Since early days, various graft materials have been tried for the closure of the tympanic membrane perforation. Temporalis fascia has been used commonly with good results. However cartilage grafts are now coming up as a primary alternative. Fascia has the advantage of being thin and transparent in nature with ease of harvesting and is readily available. Whereas the cartilage graft offers good tensile strength with a high elastic modulus, thus making it a versatile graft. ${ }^{2}$

Audiological evaluation including Pure Tone Audiogram (PTA) and Impedence audiometry in the post-operative period helps to assess the graft material. The change of the tympanometric curve from $\mathrm{B}$ to $\mathrm{A}$ or $\mathrm{C}$, indicate the closure of the perforation. The gain in Air-Bone Gap in the PTA gives an idea of the acoustic transfer allowed by different grafts used. The goal of improving the results of tympanoplasty is important for the ENT surgeon to ensure a dry ear with good hearing outcome. The success rate of tympanoplasty for Chronic otitis media mucosal disease has not been uniformly evaluated in literature. This study was aimed to evaluate the functional and audiological outcomes of type I tympanoplasty performed with temporalis fascia graft and cartilage graft.

\section{Aim}

The aim of this study was as follows:

- To compare the morphological and audiological outcome in Type I Tympanoplasty using temporalis fascia graft and cartilage graft in patients with Chronic Otitis Media mucosal disease

\section{Materials and Methods}

Study Design: Prospective comparative study

Study Setting: Department of

Otorhinolaryngology, Government Medical College, Thiruvananthapuram, Kerala

Study Subjects: Patients with Chronic Otitis Media mucosal disease posted for Type I Tympanoplasty with or without cortical mastoidectomy in the Department of ENT, Government Medical College, Thiruvananthapuram.

Study Period: January 2017 to June 2018 Sample Size

Sample size calculated using the formulae

$$
\mathrm{n}=\underline{(\mathrm{Z1}-\alpha / 2+\mathrm{Z1}-\beta)^{2}(\mathrm{P} 1 \mathrm{Q} 1+\mathrm{P} 2 \mathrm{Q} 2)}
$$

$\mathrm{Z1}-\alpha / 2$ - power of study

Z1-B - confidence of study

$\mathrm{P} 1$ - success rate with temporalis fascia graft

P2 - success rate with cartilage graft

$\mathrm{Q} 1$ is $1-\mathrm{P} 1$

$\mathrm{Q} 2$ is 1-P2

Sample size was derived from the previous study, Temporalis fascia graft vs. Cartilage graft in myringoplasty conducted by Haitham A. Alnori and Ali A. Muttalib ${ }^{3}$

$Z 1-\alpha / 2=1.96$ with confidence interval of $95 \%$

$\mathrm{Z} 1-\beta=0.82$

And the sample size was found to be 50 for each group

\section{Inclusion Criteria}

- Patients with Chronic otitis media mucosal disease posted for type 1 Tympanoplasty with or without cortical mastoidectomy who are willing to give consent for participation in the study

- Patients more than 12 years and less than 60 years.

\section{Exclusion Criteria}

- Patients who have sensorineural hearing loss.

- Patients with small central perforation with no significant hearing loss. 


\section{Data Collection Tools}

1. Proforma

2. Otoscopic Findings

3. Tuning Fork Test

4. Pure Tone Audiometry

5. Tympanometry

\section{Method}

All patients posted for Type I Tympanoplasty with or without cortical mastoidectomy for Chronic Otitis Media Mucosal Disease were included in the study after obtaining consent for participation in the study. The data regarding preoperative disease, size and site of perforation, middle ear status, ossicular status, surgical approach, graft material used, adjunctive procedures, pre and postoperative morphological (otoscopy) and audiological (hearing evaluation by Tuning Fork Test and Pure-Tone Audiogram) results were taken and analysed. The Tuning fork tests- Rinne test, Weber test and Absolute bone conduction test were performed with tuning forks of $256 \mathrm{~Hz}, 512$ $\mathrm{Hz}$ and $1024 \mathrm{~Hz}$. The size of perforation was classified into small, moderate or large depending on the involvement of one quadrant, two quadrants and three or more than three quadrants respectively. ${ }^{4}$ Subtotal perforation has only a rim of pars tensa. Tragal, conchal or preserved nasal septal cartilage was used as cartilage graft in the study. It was sliced to make an approximate thickness of $0.5 \mathrm{~mm}$ using the cartilage slicer. Postaural and transcanal approaches were used. The cases were done using operating microscope or 0 degree endoscopes.

A week following the procedure, patients were assessed for any postoperative complications. They were also followed up after 3 months and 6 months. At $3^{\text {rd }}$ month, patients were assessed for perforation closure and audiological evaluation by Tuning Fork Test and Pure Tone Audiometry. At $6^{\text {th }}$ month patients were subjected to clinical examination for integrity of tympanic membrane and PTA \& Tympanometry to assess the audiological outcome following the procedure. A successful outcome was defined as an improvement in Air-bone gap of $10 \mathrm{~dB}$ in Pure Tone Audiogram and closure of tympanic membrane perforation. Tympanometric curve of $\mathrm{A}$ or $\mathrm{C}$ defines success.

\section{Ethical Considerations}

1. Written informed consent was obtained from all study participants.

2. Confidentiality was maintained regarding data given by the participants.

- Approval from Hospital authorities obtained

- Clearance from Ethics Committee obtained

\section{Results}

A total of 110 patients were included in the study. Post operatively they were evaluated till the $6^{\text {th }}$ month.

- Morphological success rate as intact tympanic membrane was significantly higher with cartilage graft $(94.2 \%)$ as compared to temporalis fascia (67.2\%)(fig.1)

Table 1 Status of graft

\begin{tabular}{|l|l|l|l|l|}
\hline \multirow{2}{*}{$\begin{array}{l}\text { Status of } \\
\text { graft(Otoscopy) }\end{array}$} & \multicolumn{2}{|l|}{ Temporalis fascia } & \multicolumn{2}{l|}{ Cartilage graft } \\
\cline { 2 - 5 } & No. & Percent & No. & Percent \\
\hline Perforation & 19 & 32.8 & 3 & 5.8 \\
\hline Intact & 39 & 67.2 & 49 & 94.2 \\
\hline
\end{tabular}

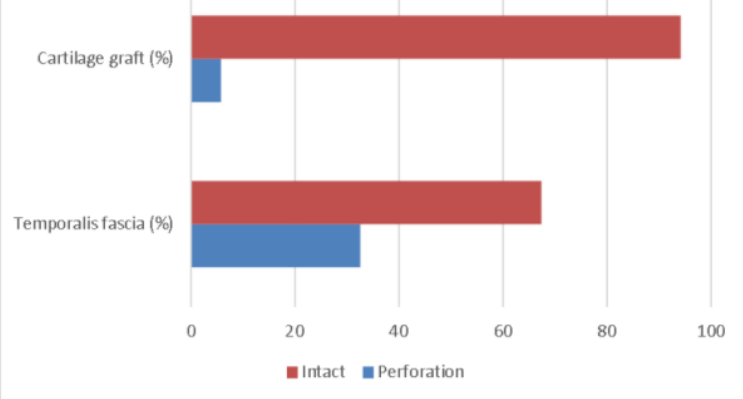

Figure 1 Status of graft

An intact tympanic membrane was seen in $94.2 \%$ of patient in whom cartilage graft was used and only in $67.2 \%$ of patients with temporalis fascia. Hence cartilage graft has significantly higher uptake compared to temporalis fascia. The significance was proved with $\mathrm{p}<0.001$. 
- Significant difference was found in tympanometric outcome between temporalis fascia and cartilage grafts. $53 \%$ patients with cartilage graft and $47 \%$ with temporalis fascia had Type A or C curve in tympanometry. (fig.2)

Table 2. Tympanometric outcome

\begin{tabular}{|c|c|c|c|c|}
\hline \multirow{2}{*}{$\begin{array}{c}\text { Tympanometric } \\
\text { curve }\end{array}$} & \multicolumn{2}{|c|}{ Temporalis fascia } & \multicolumn{2}{c|}{ Cartilage graft } \\
\cline { 2 - 5 } & No: & Percent & No: & Percent \\
\hline $\begin{array}{c}\text { Type A or C } \\
\text { curve }\end{array}$ & 39 & 47 & 44 & 53 \\
\hline Type B curve & 19 & 70.4 & 8 & 29.6 \\
\hline
\end{tabular}

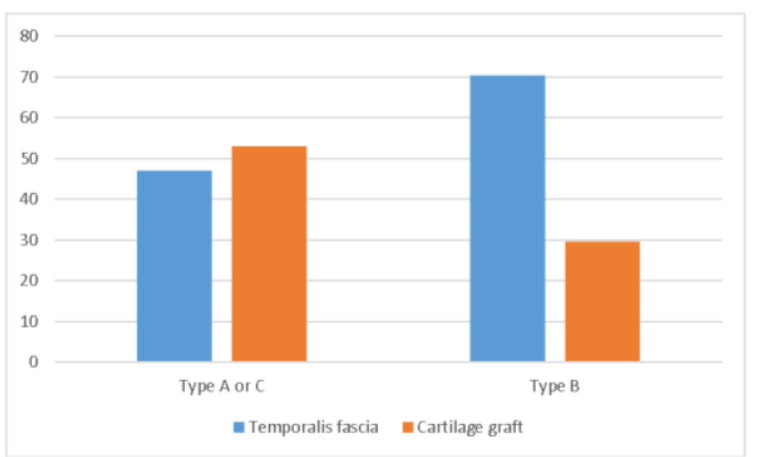

Figure 2. Tympanometric outcome

39 cases with temporalis fascia had type A or C curve and 19 cases had type B curve. 44 cases with cartilage graft had type A or $\mathrm{C}$ curve and 8 cases had B curve. This was found to be statistically significant using Chi Square test with $\mathrm{p}=0.035$.

- Audiological outcome was better with cartilage graft than with temporalis fascia. It could probably be due to the fact that thin sliced graft was used in the study giving a better acoustic transfer.(fig.3)

Table 3 Audiological outcome

\begin{tabular}{|l|c|c|c|c|}
\hline \multirow{2}{*}{ Graft } & \multicolumn{2}{|c|}{ Success } & \multicolumn{2}{c|}{ Failure } \\
\cline { 2 - 5 } & No. & Percent & No. & Percent \\
\hline $\begin{array}{l}\text { Temporalis } \\
\text { fascia }\end{array}$ & 48 & 82.8 & 10 & 17.2 \\
\hline Cartilage & 49 & 94.2 & 3 & 5.8 \\
\hline
\end{tabular}

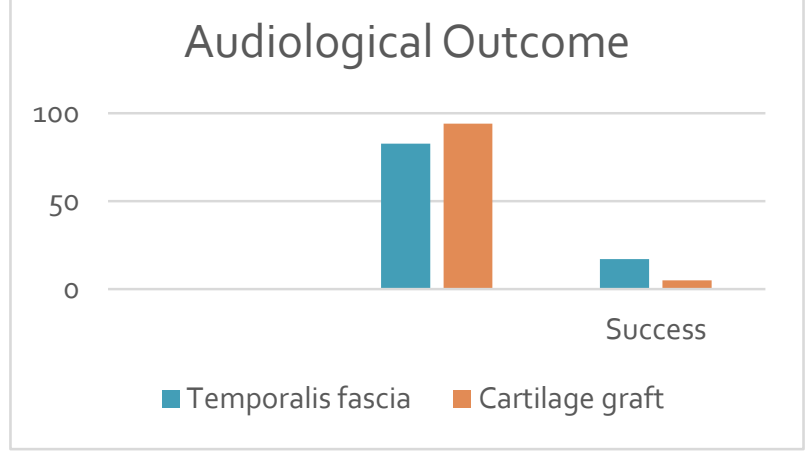

Figure 3. Audiological outcome

Cartilage graft showed significant improvement in post-operative $\mathrm{AB}$ gap gain. (94.2\%) which includes all patients with $\mathrm{AB}$ gap gain more than $10 \mathrm{~dB}$. Audiological success rate with temporalis fascia graft was $82.8 \%$. Statistical significance was proved with $\mathrm{p}=0.012$ with Chi-square test

- The role of tympanoplasty alone and tympanoplasty done along with cortical mastoidectomy in chronic otitis media in terms of graft uptake was also analysed .(fig.4)

Table 4 Type of surgery and morphological outcome

\begin{tabular}{|l|c|c|c|c|c|c|c|c|}
\hline \multirow{2}{*}{} & \multicolumn{4}{|c|}{ Temporalis fascia } & \multicolumn{4}{c|}{ Cartilage graft } \\
\cline { 2 - 9 } & \multicolumn{2}{|c|}{ Perforation } & \multicolumn{2}{|c|}{ Intact } & \multicolumn{2}{c|}{ Perforation } & \multicolumn{2}{c|}{ Intact } \\
\cline { 2 - 9 } & No. & Percent & No. & Percent & No. & Percent & No. & Percent \\
\hline $\begin{array}{l}\text { Cortical } \\
\text { mastoidectomy+ } \\
\text { tympanoplasty }\end{array}$ & 7 & 35 & 13 & 65 & 1 & 3.1 & 31 & 96.9 \\
\hline $\begin{array}{l}\text { Tympanoplasty } \\
\text { alone }\end{array}$ & 12 & 31.6 & 26 & 68.4 & 2 & 10 & 18 & 90 \\
\hline
\end{tabular}

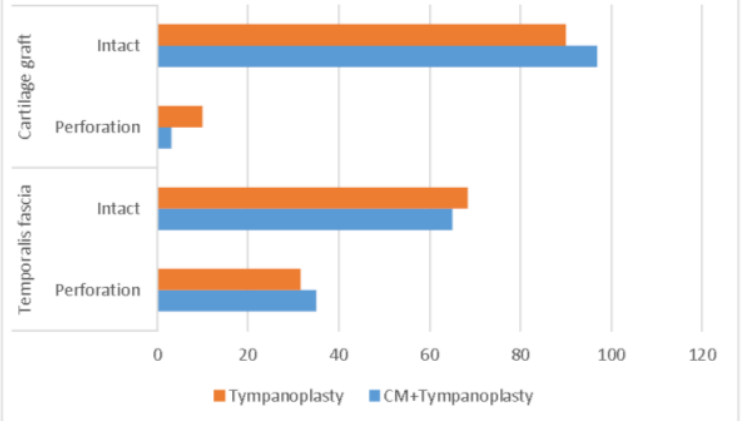

Figure 4 Type of surgery and morphological outcome

There is no significant difference in the morphological outcome when tympanoplasty 
alone was done versus cortical mastoidectomy with tympanoplasty with cartilage graft and temporalis fascia graft.

- Tympanosclerosis causes conductive hearing loss. When audiological outcome was assessed, failure rate was more in cases with tympanosclerosis $(20.8 \%)$ than without tympanosclerosis (16.4\%).

\section{Discussion}

Chronic otitis media is clinically diagnosed from history of long standing discharging ear with associated hearing loss. In mucosal disease, there is perforation of pars tensa with or without inflammation of the middle ear. The surgical management is by tympanoplasty with or without mastoidectomy. Various materials are used as graft for tympanic membrane repair. In this study, an attempt was made to compare the audiological and morphological success of type 1 tympanoplasty with or without mastoidectomy using temporalis fascia and cartilage graft.

42 males and 68 females were included in the study with a male: female ratio of 0.6:1. A similar female preponderance was noticed in the study conducted by Kazikdas et $\mathrm{al}^{5}$ with 33 females and 18 males. The mean age of patients in this study was 30 years which was also similar to the study conducted by Kazikdas et $\mathrm{al}^{5}$ where the mean age was 27.6 years. The commonest presenting complaint was otorrhea (100\%) followed by hearing loss (69.1\%) $12.7 \%$ of patients had ringing sensation of the ear, $4.5 \%$ had vertigo and $5.4 \%$ had associated ear ache. In the study conducted by Sharma $\mathrm{N}$ et $\mathrm{al}^{6}$ the commonest presenting complaint was ear discharge (100\%) followed by hearing loss (95\%), tinnitus $(6.25 \%)$ and earache $(3.75 \%)$, none had vertigo. Majority of the patients had a long standing disease with duration ranging from 3 months to 40 years.

In this study the tympanic membrane findings were divided as moderate central perforation, large central perforation and subtotal perforation based on the otoscopic examination. Large central perforation was the commonest (48.2\%) followed by moderate central perforation $(28.2 \%)$. Similar finding has been described in study conducted by VV Harkare et al. ${ }^{7}$

All the patients were evaluated pre operatively by Pure Tone Audiogram. The degree of hearing loss was categorized into three different groups based on Pure tone average i.e. $0-20 \mathrm{~dB}, 21-40 \mathrm{~dB}$ and 41-60 dB. In this study 6.4\%, $52.7 \%$ and $40.9 \%$ of the patients had hearing loss ranging from 0-20 $\mathrm{dB}, 21-40 \mathrm{~dB}$ and 41-60 dB respectively. 58 cases underwent tympanoplasty with temporalis fascia graft while 52 cases underwent tympanoplasty using cartilage graft.

Out of the 110 patients, 52 underwent cortical mastoidectomy with tympanoplasty and 58 underwent tympanoplasty alone. In patients who underwent cortical mastoidectomy with tympanoplasty, $20(38.5 \%)$ had temporalis fascia as graft and $32(61.5 \%)$ had cartilage graft. Intraoperatively 24 out of 110 patients $(21.8 \%)$ had tympanosclerosis. Association of tympanosclerosis has been mentioned in the study by Batni $\mathrm{G}$ et $\mathrm{al}^{8}$ in which 4 cases out of 88 had tympanosclerosis.

The success in this study was defined by audiological and morphological criteria. Audiological success is defined as an improvement in AB gap of at least $10 \mathrm{~dB}$ in PTA. ${ }^{9}$ The AB gap is calculated in speech frequency i.e. $500 \mathrm{~Hz}, 1 \mathrm{KHz}$ and $2 \mathrm{KHz}$. Morphological success was defined as an intact tympanic membrane and A or $\mathrm{C}$ curve on Tympanometry at the end of 6 months after surgery. Various associations with the morphological and audiological outcomes have been studied. The tympanometric outcome on using Cartilage graft and Temporalis fascia was compared. $47 \%$ with temporalis fascia graft, had a successful outcome by having an A or $\mathrm{C}$ curve while $70.4 \%$ had a $\mathrm{B}$ curve. In patients whom a cartilage graft was used, 53\% had a successful outcome in terms of having A or C curve, while $29.6 \%$ had a B curve. Significance was found ( $\mathrm{p}=0.035$ ) using Chi Square test. Of the patients in whom cartilage graft was used, $94.2 \%$ had an intact tympanic membrane at the end of 6 
months, while $67.2 \%$ of the patients grafted with temporalis fascia had an intact membrane. This parameter was statistically significant $(\mathrm{p}=0.00)$. Here $32.8 \%$ of those with temporalis fascia graft and $5.7 \%$ of those with cartilage graft had perforation. It is similar to the result obtained by Yegin $\mathrm{Y}$ et $\mathrm{al}^{10}$ where graft success with cartilage graft was $91.3 \%$ with $\mathrm{p}=0.01$. In the study conducted by Aneesa A M et $\mathrm{al}^{4}$ cartilage graft had an uptake of $92.4 \%$ whereas temporalis fascia had $80 \%$ uptake at 6 months of follow up. According to Lacovou $\mathrm{E}$ et $\mathrm{al}^{11}$, there was significant success in hearing results with cartilage graft here the mean graft integration rate was $92.4 \%$ in cartilage group and $84.3 \%$ in temporalis fascia group.

The successful audiological outcome is a gain in AB gap of $10 \mathrm{~dB} .{ }^{9}$ Statistically cartilage graft had good audiological outcome $(94.2 \%)$ compared to temporalis fascia $(82.8 \%)(\mathrm{p}=0.012)$ in this study. In the study conducted by Yegin $\mathrm{Y}$ et al., $\mathrm{AB}$ gap gain in cartilage group (7.51) was more than the gain in the temporalis fascia graft group (4.68), it was significant $(\mathrm{p}=0.046) 43$. Alnori $\mathrm{H}$ et al. study showed the percent improvement in mean $\mathrm{AB}$ gap was more for fascia than cartilage graft $(\mathrm{p}=$ 0.001 ). An improvement of $19.6 \mathrm{~dB}$ was noted in temporalis fascia and that of cartilage graft was $15.7 \mathrm{~dB}$. In the study conducted by Aneesa AM et al. ${ }^{4}$ Air-bone gap in fascia group showed a closure to $10 \mathrm{~dB}$ in $17.5 \%$ of patients and in the cartilage group, $10 \mathrm{~dB} \mathrm{AB}$ gain was seen in $25 \%$ of patients. $^{4}$

In study conducted by Ulku et al ${ }^{12} 91.3 \%$ success rate of graft uptake in cartilage vs. fascia $88.2 \%$ and hearing gain of $12.3 \%$ in cartilage and $12.7 \%$ in fascia in cases of type 1 tympanoplasty. Albirmawy et $\mathrm{al}^{13}$ has reported a case series in type 1 tympanoplasty where the morphological success rate in cartilage $95 \%$ vs. fascia $76.2 \%$. Mean postoperative air bone gap $10.95+/-2.12 \mathrm{~dB}$ in cartilage versus $12.73+/-8.97$ in fascia. No significant difference in hearing between two groups.Chabra et $\mathrm{al}^{14}$ showed $90 \%$ of patients with cartilage shield tympanoplasty and $88 \%$ with temporalis fascia had significant improvement in hearing $\mathrm{ABG}>10 \mathrm{~dB}$ )

The relationship between the duration of disease and hearing loss was assessed. It showed that the longer the duration of the disease, more is the $\mathrm{AB}$ gap in the Pure Tone Audiogram. The relationship between duration of the disease with graft used have also been assessed and comparable results were obtained. Both the grafts were used for long standing disease.

The evaluation of tympanosclerosis with preoperative hearing loss was done. But since the number of patients with tympanosclerosis was limited no association could be made. The association of tympanosclerosis with postoperative improvement in $\mathrm{AB}$ gap was also assessed. The improvement in $\mathrm{AB}$ gap was comparable but failure was more in patients with tympanosclerosis $(20.8 \%)$. The failure in cases without tympanosclerosis was $16.3 \%$. Tsuzuki $\mathrm{K}$ et $\mathrm{al}^{15}$ showed significantly improved hearing results after removal of tympanosclerosis in Tympanoplasty.

The morphological outcome of tympanoplasty alone and cortical mastoidectomy with tympanoplasty for cartilage graft and temporalis fascia graft was compared. Morphological outcome with temporalis fascia was comparable in both surgeries, success rate was $65 \%$ for Tympanoplasty with Cortical Mastoidectomy and $68.4 \%$ for Tympanoplasty. Success rate with cartilage graft for Tympanoplasty with Cortical Mastoidectomy was $96.9 \%$ and Tympanoplasty alone was $95 \%$.

\section{Conclusion}

Cartilage graft is superior to temporalis fascia graft with regard to good morphological and audiological outcomes. It has better graft uptake and improved hearing.

\section{Reference}

1. WHO. Chronic suppurative otitis media Burden of Illness and Management Options. WHO Libr Cat Data [Internet]. 
$2004 ; 84$.

Available

from:

http://www.who.int/pbd/publications/Chro nicsuppurativeotitis_media.pdf

2. Yang T, Wu X, Peng X, Zhang Y, Xie S, Sun H. Comparison of cartilage graft and fascia in type 1 tympanoplasty: systematic review and meta-analysis. Acta Otolaryngol. 2016;136(11):1085-90.

3. Alnori HA, Mohammed AAM, Alhamdani RM. Temporalis Fascia Versus Cartilage Graft in Myringoplasty = الـ لـ إف

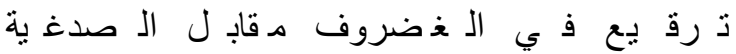
Jordan Med J. 2016;48(2):113-20

4. Aneesa AM, Pillai A, Rajamma KB. Outcome of Type 1 Tympanoplasty with Cartilage-perichondrium Graft in Comparison with Temporalis Fascia [Internet]. Vol. 62, International Journal of Scientific Study. 2019 [cited 2019 May 8]. Available from: www.ijss-sn.com

5. Kazikdas KC, Onal K, Boyraz I, Karabulut E. Palisade cartilage tympanoplasty for management of subtotal perforations: A comparison with the temporalis fascia technique. Eur Arch Oto-RhinoLaryngology. 2007;264(9):985-9.

6. Sharma N, Sharma P, Sharma P, Gourav K, Goyal VP. Comparison of otological and audiological outcome of type-I tympanoplasty using composite tragal perichondrium and temporalis fascia as graft. Int J Otorhinolaryngol Head Neck Surg [Internet]. 2018 Aug 25 [cited 2019 May 6];4(5):1182. Available from: http://www.ijorl.com/index.php/ijorl/articl e/view/1112

7. Vivek V Harkare, Rakesh K Mishra, Nitin V Deosthale, Sonali P Khadakkar, Priti R Dhoke, Kanchan Dhote, Nudrat Kamal, Sudheer T Reddy. "A comparative study of different tissues used for tympanic membrane grafting". Journal of Evolution of Medical and Dental Sciences 2013; Vol. 2, Issue 41, October 14; Page: 7834-7840.
8. Batni G, Goyal R. Hearing outcome after type I tympanoplasty: a retrospective study. Indian J Otolaryngol Head Neck Surg [Internet]. 2015 Mar [cited 2019 May 10];67(1):39-42. Available from: http://www.ncbi.nlm.nih.gov/pubmed/256 21230

9. Dabholkar JP, Vora K, Sikdar A. Comparative study of underlay tympanoplasty with temporalis fascia and tragal perichondrium. Indian J Otolaryngol Head Neck Surg [Internet]. 2007 Jun [cited 2019 May 9];59(2):116. Available from: http://www.ncbi.nlm.nih.gov/pubmed/231 20407

10. Yegin Y, Çelik M, Koç AK, Küfeciler L, Elbistanlı MS, Kayhan FT. Comparison of temporalis fascia muscle and full-thickness cartilage grafts in type 1 pediatric tympanoplasties. Braz J Otorhinolaryngol. 2016;82(6):695-701.

11. Iacovou E, Vlastarakos P V., Papacharalampous G, Kyrodimos E, Nikolopoulos TP. Is cartilage better than temporalis muscle fascia in type I tympanoplasty? Implications for current surgical practice. Eur Arch Oto-RhinoLaryngology [Internet]. 2013 Nov 16 [cited 2019 May 10];270(11):2803-13. Available from: http://link.springer.com/10.1007/s00405012-2329-4

12. Ulkü $\mathrm{CH}$. Cartilage tympanoplasty with island technique for reconstruction of tympanic membrane perforation: anatomic and audiologic results. Kulak Burun Bogaz Ihtis Derg [Internet]. [cited 2019 May 11];20(1):7-12.

13. Albirmawy OA. Comparison between cartilage-perichondrium composite 'ring' graft and temporalis fascia in type one tympanoplasty in children. J Laryngol Otol [Internet]. 2010 Sep 20 [cited 2019 May 11];124(9):967-74. Available from: 
http://www.ncbi.nlm.nih.gov/pubmed/204 03227

14. International Journal of Otorhinolaryngology and Head and Neck Surgery Chhabra $G$ et al. Int $J$ Otorhinolaryngol Head Neck Surg. 2018 Jul;4(4):951-955 http://www.ijorl.com

15. Tsuzuki K, Yanagihara N, Hinohira Y, Sakagami M. Tympanosclerosis involving the ossicular chain: Mobility of the stapes in association with hearing results. Acta Otolaryngol. 2006;126(10):1046-52. 